\title{
VINCULACIÓN DE CUESTIONES. LA RELACIÓN DE ARGENTINA CON ESTADOS UNIDOS DURANTE SU DES-ENDEUDAMIENTO
}

\author{
ROBERTO MIRANDA ${ }^{1}$ \\ UNIVERSIDAD NACIONAL DE ROSARIO
}

ARGENTINA 


\title{
RESUMEN
}

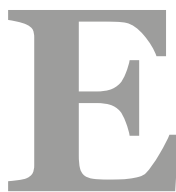

lobjetivo de este trabajo es analizar la relación de Argentina con Estados Unidos sobre la base de la cuestión del default que afectó al país latinoamericano, a fin de determinar su nivel de autonomía en esa relación, y si tal nivel fue efectivo. Al respecto entendemos que la citada autonomía enhebrada durante el des-endeudamiento fue aparente, pues el gobierno estadounidense reforzó la situación de dependencia de Argentina a través de su interposición para que éste país no accediera a la inversión y financiamiento transnacionales. En este análisis consideramos los motivos y las condiciones a través de las cuales el poder estadounidense le hizo sentir a Argentina la pertenencia a su esfera de influencia.

Palabras Claves: Argentina, Estados Unidos, Bilateralismo, Des-endeudamiento, Dependencia.

\begin{abstract}
The purpose of this paper is to analyse the relationship of Argentina with the United States on the basis of the default issue that affected the Latin American country in order to determine their level of autonomy in that relationship, and if such level was effective. In this regard we understand that this autonomy threaded throughout the un-indebtedness period was apparent, because the American government reinforced the situation of dependence of Argentina by interposing itself in a manner that this country did not accede to transnational investment and financing. In this analysis we consider the reasons and conditions through which the American power made Argentina felt its belonging to America's sphere of influence.
\end{abstract}

Key words: Argentina, United States, Bilateralism, Un-indebtedness, Dependence.

\section{INTRODUCCIÓN}

En la primera década del presente siglo, Argentina procuró poner fin al alineamiento con Estados Unidos que había sido uno de los postulados de su política exterior durante los noventa. Este intento significó la búsqueda de una mayor capacidad decisional para definir sus políticas públicas, como así también para obtener un mejor margen de maniobrabilidad inter- 
nacional. Por su parte el gobierno estadounidense, tanto por razones económicas como por el episodio del 11-S, no tuvo entre sus prioridades a América Latina y menos aún a Argentina. La diferencia de realidades y de sintonía entre Argentina y Estados Unidos configuró un esquema de relaciones bilaterales con altibajos. Sin embargo hubo una cuestión sobre la cual convergieron ambos actores, como fue la necesidad de resolver el default del país sudamericano.

El objetivo de este trabajo es analizar la relación de Argentina con Estados Unidos sobre la base de la cuestión de la cesación de pagos, a fin de determinar su nivel de autonomía en esa relación, y si tal nivel fue efectivo. La resolución del default implicó una nueva etapa en la relación entre ambos países, y Argentina asumió el des-endeudamiento como una posibilidad cierta para moderar su situación de dependencia con Estados Unidos. La expectativa giró en torno a la creencia de que la cancelación de los pasivos equivalía a alcanzar metas autonomistas. Entre tales metas estaba la de poder moverse libremente con el propósito de encontrar el financiamiento más adecuado para un potencial aparato productivo basado en el desarrollo industrial. Esta intención debió coexistir con la realidad de que Argentina, a pesar de la post Guerra Fría, globalización y regionalización sudamericana, seguía formando parte de la esfera de influencia de Estados Unidos.

Algunos estudios e investigaciones sobre la política de des-endeudamiento argentino, han destacado que gracias a esta política el país logró mayor autonomía en el plano internacional. Por ejemplo se sostuvo que más allá del discurso de cuestionamiento a los organismos multilaterales de crédito, a fines de 2007 Argentina pudo superar el "reducido margen de acción que había caracterizado la situación del país” de principios de siglo (Torres, 2011:116). A propósito de esta afirmación, el mismo analista calificó a la cancelación de deuda externa como una postura pragmática que, por caso, trascendió la crisis financiera mundial de 2008, facilitando "la búsqueda de mayor autonomía" para el país (Torres, 2009:129). Precisamente desde una perspectiva afín, se subrayó que el des-endeudamiento fue positivo, porque redujo la "exposición de la economía a los vaivenes de los mercados internacionales de capital", permitiendo -de esta manera- "la obtención de mayores márgenes de autonomía" para "consolidar un proceso de desarrollo nacional” (Nemiña, 2012:84).

Otro punto de vista similar entendió que el gobierno argentino estaba convencido de que el pago de la deuda al Fondo Monetario Internacional (FMI) fue un claro respaldo a su objetivo de "ampliar los márgenes de maniobra del país" en el contexto externo (Simonoff, 2009:82). Para Daniel Morales Ruvalcaba (2010:32), Argentina diseñó una estrategia de "geoeconomic buffering (amortiguamiento geoeconómico) contra el FMI, es decir, para la reducción de la influencia de las potencias mundiales en espacios regionales", de modo tal que la postura del país latinoamericano -según este autor- fue de "relativa autonomía, no de enfrentamiento abierto" con esas potencias, sino de autonomía heterodoxa. En líneas generales todos estos puntos de vista consideraron a la política de des-endeudamiento como una palanca a través 
de la cual Argentina obtuvo autonomía frente a los medios multilaterales de crédito, pero muy primordialmente ante Estados Unidos (Bologna, 2010:44-45).

Sin embargo otros enfoques afirmaron "que desde la renegociación de la deuda, Argentina no ha usado su gestión externa en forma exitosa para adoptar soluciones a sus necesidades internas" y, por otra parte, que el país perdió importancia a nivel regional lo cual implicó "menor relevancia ante Washington” (Busso, 2009:50). Este fue uno de los motivos por los cuales la relación bilateral de Argentina con el gobierno norteamericano -según la citada estudiosatuvo "un carácter neutro" cuando a pesar de todo lo ocurrido en los noventa y la crisis de 2001, Estados Unidos aún seguía siendo prioridad en la política exterior del país latinoamericano. En otras palabras, la salida de Argentina de la mayor parte de su default no modificó la tradición espasmódica que regía su relación bilateral con el hegemón. Enfoques similares al de Anabella Busso concluyeron en que el des-endeudamiento, en el marco de una "confianza bilateral escasa", no entusiasmó a Estados Unidos para abrir "puertas a un retorno del gobierno argentino al mercado financiero internacional” (De la Balze, 2010:126).

Justamente Argentina, a pesar de los resultados obtenidos a través de la modificación de la estructura del endeudamiento, "no consiguió sellar de inmediato su reinserción a los circuitos financieros globales” (Fernández Alonso, 2006:84). Vale añadir que tampoco logró este cometido luego de la segunda operación de canje de bonos en default, en 2010. Como señalamos más arriba, los altibajos en la relación bilateral con Estados Unidos fueron una de las trabas al acceso argentino al crédito internacional. Este bilateralismo, además de tener "carácter neutro", según otro punto de vista se definió como una "relación distante" que terminó siendo más perjudicial para Argentina que -obviamente- para la gran potencia (Russell, 2010). De acuerdo a estas últimas interpretaciones, la tensión político-diplomática entre ambos países fue decisiva para que las relaciones bilaterales no se potenciaran. Precisamente en el momento de la renegociación de la deuda, una de las impresiones estadounidenses era que Argentina quedaba subordinada al Mercosur, y que por lo tanto su relación política con Estados Unidos iba a pasar por Brasil (Falcoff, 2004:78-79).

El intercambio comercial entre ambos países también reflejó los altibajos de la relación bilateral. Sin embargo es importante señalar que este intercambio se inclinó a favor de la potencia hegemónica. En efecto, a partir de 2006 la balanza comercial fue deficitaria para Argentina, profundizándose significativamente este saldo negativo hacia 2010 al superar los 2.500 millones de dólares. Más de la mitad de estas exportaciones, en el período 2002-2010, se concentraron en combustibles, aluminio, bebidas y manufacturas de hierro y acero. Además del déficit, también es de destacar que la participación de Estados Unidos como destino de las exportaciones argentinas fue disminuyendo notablemente de $8.6 \%$ en 2006 a $5.2 \%$ en $2010^{2}$. 
Pero esa disminución de las exportaciones como el saldo negativo en el intercambio comercial, no preocuparon al gobierno argentino como sí le inquietó el propósito de dejar de depender de Estados Unidos y de los organismos multilaterales de crédito para acceder a las fuentes de financiamiento transnacional. Argentina a través del des-endeudamiento trató de procesar una política autonomista como han sostenido algunos estudiosos. Creyó que era posible una conexión directa con actores no estatales portadores de capital productivo, independientemente del poder político estadounidense. Los discursos presidenciales y las actitudes gubernamentales apuntaron en esa dirección, tanto en las relaciones bilaterales con distintos países como en los ámbitos multilaterales. Por otra parte el carácter "neutro" y "distante" de la relación de Argentina con Estados Unidos como señalan algunos investigadores, pareció confirmar la intención de eludir a la potencia hegemónica.

La teoría nos dice que la vocación autonomista puede estar presente en la concepción ideológica de una política exterior, como así también en las decisiones que sobre ésta política adopta un gobierno. Sin embargo esto no es suficiente. Lo significativo es si el efecto que provoca la política exterior representa autonomía. Es decir si la autonomía es proporcional a la eliminación o disminución de una situación de dependencia (Puig, 1971. Jaguaribe, 1979. Gil Villegas, 1989. Miranda, 2003). Nuestro supuesto es que la política autonomista que ensayó Argentina fue aparente, porque el poder que intentó impulsar para despejar el camino hacia el crédito transnacional no surtió el efecto esperado. Argentina no logró acceder al financiamiento, y en esta tentativa la dependencia con Estados Unidos en todo momento estuvo más que latente. Más aún, tal dependencia se reforzó porque el gobierno estadounidense le hizo sentir a Argentina que todavía formaba parte de su esfera de influencia, lo cual analizamos a continuación a través del desarrollo de los motivos y de las condiciones que enmarcaron esa realidad política. Para este desarrollo consideramos tres ejes que explican la condición argentina, uno es el gobierno estadounidense, otro es la mesa tripartita de la negociación, y por último la cuestión política de la inversión extranjera directa.

\section{EL QUIEBRE}

Es cierto que Argentina acumuló numerosos desaciertos políticos y económicos que la empujaron a la crisis de diciembre de 2001. Sin embargo contrariamente a lo que suele sostenerse, no fueron las desprolijidades financieras las que quebraron la alianza de poder con Estados Unidos, enhebrada por los gobiernos de Carlos Menem y a la cual le dio continuidad la gestión de Fernando De la Rúa. Fue Estados Unidos quien rompió esa alianza a través de la indiferencia política que avivó frente al desmoronamiento argentino. Por supuesto que no fue casual. A mediados de 2000 la 
economía norteamericana comenzó una etapa recesiva después del esplendor alcanzado durante los noventa, en gran medida motorizado por la sobreproducción, particularmente de la industria de la tecnología de la información y de la comunicación. Una recesión que la Reserva Federal estadounidense intentó paliar con una rápida reducción de las tasas de interés.

Pero en 2001 no sólo el golpe terrorista de Al-Qaeda estremeció a Estados Unidos³. También su economía sacudió al país al registrar tres trimestres consecutivos de tasas negativas lo cual repercutió internacionalmente, con el agravante de la corrupción en grandes empresas como la energética Enron Corporation y la de telecomunicaciones WorldCom, las cuales terminaron quebrando, la primera a mediados de 2001 y la otra en julio del año siguiente. La crisis norteamericana que derivó en una crisis financiera internacional no sólo profundizó la recesión iniciada en Argentina en 1998, también le recordó a este país su condición periférica, porque justamente fue esquivado cuando se consideraba que a través de él las políticas del Consenso de Washington habían fracasado. La excusa dada desde el Congreso estadounidense de que la economía argentina había pasado de recesiva a depresiva no fue convincente. Para el gobierno estadounidense, Argentina ya no tenía el valor político que supuestamente le había asignado en los noventa, y por lo tanto la alianza de poder perdía vigencia. En esa circunstancia el economista Walter Molano, de BCP Security, fue muy claro al decir que el FMI a instancias de Estados Unidos sólo le podría haber dado dinero "a Turquía o a países de mayor importancia estratégica".

El secretario del Tesoro, Paul O’Neill, representó la indiferencia política de Estados Unidos hacia la situación financiera argentina. Para abandonar esa indiferencia le impuso a Argentina como condicionamiento que reprogramara su deuda externa a través de un acuerdo con el FMI. Una actitud muy distinta a la que tuvo con Brasil, porque para éste país no dudó en presionar sobre el organismo financiero multilateral a fin de que le otorgara un préstamo por 30.000 millones de dólares, en setiembre de 2002, el mayor crédito otorgado hasta ese momento por la institución con el objeto de sostener una política económica. En cambio el planteo que Washington le formuló a Argentina fue una complicación para el gobierno provisional de Eduardo Duhalde, porque las exigencias del FMI destinadas a negociar un acuerdo eran excluyentemente técnicas, muy lejos del esquema esbozado por el ministro de Economía, Jorge Remes Lenicov. Eran exigencias propias de la burocracia de la institución internacional, que una vez más ratificaba sus políticas de ajuste para superar una situación crítica.

El mensaje brindado por el Departamento de Estado al canciller Carlos Ruckauf sobre la posibilidad de una presión estadounidense hacia el FMI a favor de Argentina sólo fue una promesa incumplida, puesto que tal Departamento para esta situación en particular no tallaba al interior del gobierno norteamericano. El pedido de Remes Lenicov de 25.000 millones de dólares para saldar la deuda fue rechazado sin atenuantes por O’Neill, cuya opinión era decisiva en la administración de 
George W. Bush al ser, en ese momento, el funcionario de mayor peso. La indiferencia de O’Neill se basó en el desinterés por la suerte de Argentina. Una muestra de esta conducta fue el haber confesado, categóricamente, que no tenía solución para la crisis del país latinoamericano. Otra muestra fue el haberse apoyado casi exclusivamente en los informes y sugerencias del director del Departamento de Operaciones Especiales del FMI, Anoop Singh, el cual se negaba a realizar concesiones a Duhalde que estuviesen fuera de la ortodoxia del organismo internacional, envalentonado por su participación en la resolución de la crisis financiera de Indonesia de 1997, que pretendía repetir en la de Argentina.

\section{LA SEGUNDA DECISIÓN}

La posición común que tenían Estados Unidos y el FMI con respecto a Argentina se desactivó una vez que el gobierno estadounidense tomó conciencia de la envergadura de la crisis, preocupado no precisamente por el destino de aquél país en particular, sino por la escalada regional que podía adquirir tal crisis. O’Neill, más allá de Brasil, no quiso ver la situación argentina según la percibían diferentes funcionarios del gobierno de Bush, es decir, como una amenaza a la estabilidad hemisférica, principalmente a partir de junio de 2002 cuando cayeron las bolsas de Chile y México. Este registro disparó el objetivo norteamericano de que no sólo debía evitarse el efecto contagio, también debía morigerarse el nivel de afectación que la crisis argentina podía causarle a países con finanzas supuestamente prolijas. De manera que este cambio de actitud norteamericana significó una segunda decisión de Washington sobre el caso argentino, opuesta a la que en un principio había adoptado O’Neill.

Por otra parte el gobierno estadounidense decidió abandonar la regla de que cada cuestión debía ser resuelta según su propia lógica, separadamente del juego político, lo cual significaba que el endeudamiento argentino tenía que ser solucionado a través de métodos financieros. Algo similar, salvando distancias, a lo que hizo Gran Bretaña en 1890 al rechazar el pedido de inversionistas de la city londinense de intervenir políticamente en Argentina para solucionar la crisis de la Baring Brothers, cuando sostuvo que los problemas financieros debían ser resueltos mediante sus propios parámetros. Al desistir de esta regla, el gobierno estadounidense modificó sustancialmente la relación de Argentina con los acreedores. Por encima de las razones económico-financieras y diplomáticas, Estados Unidos consideró el default argentino como un problema de estabilidad al interior de su esfera de influencia geopolítica. Así puso en evidencia que Argentina dependía de su interés estratégico basado en el patrón de seguridad internacional. De manera que el tema de la cesación de pagos iba a ser tratado bajo el fundamento de la mencionada dependencia de Argentina con Estados Unidos.

La introducción de la lógica política se produjo en el momento en el cual Estados Unidos 
eligió participar activamente en la resolución del default de Argentina, empujando un asunto bilateral entre este país y el FMI a una mesa tripartita en la que el gobierno norteamericano iba a tener la conducción de esa resolución. Con esta decisión Estados Unidos se diferenció claramente del organismo multilateral. Una de las razones fue la división interna en el FMI a propósito del caso argentino. Por un lado algunos funcionarios de la institución internacional miraron con simpatía la propuesta del influyente economista y asesor de bancos de inversión, Rudiger Dornbusch, que consistía en "intervenir" la economía argentina a través de una administración llevada a cabo por expertos extranjeros. Dornbusch era pesimista sobre el destino argentino, y afirmaba que no iba "a ser un país feliz". Otros funcionarios, en cambio, apostaban al criterio de ABN Amro Bank de prestar financiamiento a Argentina mientras el país adoptara medidas internas tendientes a ordenar su economía y, de esta forma, cumplir con los requerimientos del FMI.

Otra de las razones que diferenciaron a Estados Unidos del FMI fue el interés burocrático que este organismo puso por encima del propósito real de solución de la situación argentina. El objetivo de los cuadros técnicos de la estructura multilateral, era el de ocultar las responsabilidades que había tenido el FMI en el endeudamiento de Argentina al que en su momento acompañaron con un discurso elogioso por el desempeño económico que aparentemente tenía el país. Esos cuadros técnicos, sobre todo, pretendían esconder la complicidad que habían tenido con el "blindaje" financiero como con el "megacanje", éste último orientado a prorrogar los vencimientos de deudas. Apelaron a la demonización de los gobiernos argentinos por los desaguisados económicos ocasionados por estas gestiones, como una de las principales causas de la cesación de pagos. Pero el interés burocrático todavía iba mucho más lejos. La intención era básicamente simbólica, pues se trataba de transformar al FMI en una entidad imparcial desligada de las políticas que a los gobiernos les había exigido desarrollar y que luego estos estaban impedidos de sostener. La idea de los técnicos del FMI era recuperar prestigio internacional y, al mismo tiempo, minimizar los cuestionamientos que se le hacían al organismo, para lo cual sancionaban mediáticamente a los países miembros que estaban en crisis, como era el caso de Argentina.

La decisión del gobierno estadounidense de interceder en la relación entre Argentina y el FMI formó parte de una serie de medidas que buscaron limitar el poder de O’Neill por las discrepancias que algunos funcionarios tenían con él en torno a su visión económica. Así Bush depositó en el subsecretario para Asuntos Internacionales del Departamento del Tesoro, John Taylor, el control de la participación estadounidense en la mesa tripartita ${ }^{4}$. Otra pieza que compartía esa indiferencia fue Anne Krueger, subdirectora gerente del FMI que, como es sabido, un cargo que siempre estuvo reservado a un estadounidense. Justamente contra lo que era costumbre, Krueger se alejó de la posición norteamericana cuando Bush realizó el giro, y la subdirectora se fue acercando cada vez más a los cuadros técnicos del organismo multilateral,

\footnotetext{
${ }^{\overline{4}}$ Esto significó no sólo apartar a O’Neill del caso argentino por su escepticismo, sino también eliminar la influencia del presidente del Consejo Económico Nacional, Lawrence Lindsey, que acompañaba al secretario del Tesoro en la indiferencia hacia el default del país latinoamericano.
} 
sobre todo coincidiendo con los informes y sugerencias de Singh.

Entre Taylor por un lado, y O’Neill, Lindsey y Krueger por el otro, la diferencia no era de poder político, sino de perspectiva con respecto al caso argentino. Estos últimos percibían que el caso argentino estaba desprovisto de brotes políticos, sin trascendencia internacional y que debía estar sujeto a la más estricta ortodoxia económica, tratando de emular la salida de las crisis asiáticas iniciadas en 1997. Es decir una postura distante de todo costo que no fuera monetario. En cambio Taylor encaró la cuestión no sólo a partir del riesgo regional del efecto dominó y su nivel de afectación, sino también desde la carga norteamericana de tener que articular los intereses de la banca privada transnacional, la cual realizaba un fuerte lobby en torno al Congreso estadounidense. A esto se agregaban dos datos para nada menores. Uno era la presión política de Francia y España alrededor del G-7 en defensa de los intereses puestos en Argentina a través de sus empresas, las cuales habían sido beneficiadas con las privatizaciones de los noventa. Otro dato era el reclamo de los acreedores privados de deuda argentina, los cuales les demandaban a sus respectivos gobiernos una mayor firmeza ante Estados Unidos para que éste resolviera la situación de la cesación de pagos.

\section{LAS RESPUESTAS RECÍPROCAS}

Una vez que Estados Unidos asumió la conducción de la mesa tripartita, planteó dos cuestiones políticas ante la debilidad del gobierno de Duhalde. Por un lado el cambio de ministro de Economía que implicó la llegada de Roberto Lavagna, el cual contaba con el apoyo de una amplia franja de políticos y legisladores nacionales, como así también de sectores del empresariado. Por otro lado el compromiso de Duhalde de llamar a elecciones para que no prosperara su proyecto de continuidad gubernamental, apropiándose de la posibilidad de un éxito en la salida del default. Este compromiso se vinculaba con la indisimulada antipatía que tenían hacia Duhalde tanto las estructuras del poder político norteamericano, como el ámbito financiero transnacional. Fue muy claro que las expectativas de la administración Bush estaban centradas en Lavagna; más concretamente Taylor basó su conducción en el asunto sólo a través del entendimiento con el ministro de Economía, lo cual trascendió a Duhalde y persistió durante el gobierno de Néstor Kirchner hasta que el subsecretario se retiró del Departamento del Tesoro, en abril de 2005.

Además de las cuestiones políticas, Estados Unidos puso tres condiciones que consideraba fundamentales para iniciar la negociación sobre la reprogramación de la deuda. Todas estas condiciones habían sido propuestas por el FMI. Una era la derogación de la Ley de Subversión Económica reclamada por los banqueros, los cuales suponían que la misma afectaba la compatibilidad del sistema financiero nacional con las reglas de juego internacionales. Así 
la banca coincidía con los técnicos del FMI, los cuales criticaban la citada ley porque sostenían que generaba inseguridad jurídica a la inversión. También sectores del empresariado argentino estaban a favor de la supresión de la misma, porque sin ella veían la posibilidad de obtener créditos de la Corporación Financiera Internacional del Banco Mundial. Otra condición, igualmente demandada por el FMI, era la firma de un acuerdo fiscal del gobierno nacional con las principales provincias. Por último la tercera de las condiciones que impulsaba Taylor, era la reforma de la Ley de Quiebras a través de la cual el gobierno argentino había intentado reacomodar la deuda del sector privado en emergencia productiva y crediticia, lo cual el organismo multilateral evaluaba como desproporcionada.

Argentina aceptó esas condiciones, y Estados Unidos naturalmente respaldó esa decisión con el propósito de sostener la negociación sobre la que estaba interesado en iniciar para frenar una eventual profundización de la crisis. Un ejemplo de ello fue la promesa del representante estadounidense de Comercio, Robert Zoellick, de incluir productos argentinos en el Sistema Generalizado de Preferencias para su ingreso al mercado norteamericano mediante aranceles muy bajos, o bien sin aranceles de importación. Otro ejemplo fue el haber auspiciado a favor de Argentina una prórroga del FMI de pagos de la deuda externa que vencían en julio de 2002.

Pero las réplicas más contundentes fueron dos. Por un lado el apartamiento de Singh del caso argentino y su sustitución por John Thorton. Esto fue así porque Taylor dio un consentimiento implícito a la queja formal presentada por Argentina ante el FMI en la que identificó a Singh como el responsable de deformar la posición de la banca ante las decisiones del gobierno, poniendo "en situación de riesgo" las negociaciones, según rezaba la mencionada queja. Por otro lado el anuncio norteamericano de que era posible la firma de un acuerdo provisorio con el fin de distender la relación entre Argentina y el FMI. Para darle consistencia a este anuncio, tanto el subsecretario de Estado para Asuntos Económicos, Alan Larson, como el subsecretario de Estado y segundo en la línea jerárquica de la cancillería norteamericana, Richard Armitage, anticiparon que Argentina iba a superar las dificultades financieras siendo uno de los principales aliados de Estados Unidos fuera de la Organización del Tratado del Atlántico Norte (OTAN). Obviamente que este respaldo no estuvo inspirado en una valoración política de Argentina, sino en una evocación alegórica destinada a reducir la imagen de vulnerabilidad internacional que tenía el país para mostrar ante el mundo que el mismo era apoyado por Estados Unidos.

\section{SÓLO LA NEGOCIACIÓN}

La negociación sobre la reprogramación de la deuda fue muy extensa y extremadamente complicada. Previo a considerar las características de esta negociación, vale preguntarse por 
qué Argentina había aceptado de Estados Unidos condiciones similares a las que en su momento el FMI le había sugerido a Remes Lenicov, el cual las rechazó abiertamente. Diferente al organismo multilateral, Estados Unidos presentó una perspectiva política para afrontar la citada negociación. Fue así porque el hegemón tuvo en cuenta aspectos importantes que de manera directa o indirecta incidían en su política internacional, como la cuestión de la estabilidad hemisférica, o bien la tenaz resistencia que ofrecían los países desarrollados agrupados en el G-7 a suavizar las exigencias sobre Argentina; y también tuvo en cuenta aspectos que repercutían en su política doméstica, como la presión de los llamados "fondos buitre" que merodeaban el Congreso norteamericano mediante algunos lobbies.

Tanto la firma del acuerdo provisorio de enero de 2003, como el cierre del definitivo sellado en setiembre del mismo año, fueron posibles por la cobertura política que Taylor impuso a la negociación con la complicidad de Lavagna, lo cual estaba entre las expectativas del ministro de Economía argentino. En ese marco la recuperación de la economía argentina jugó un papel más que importante porque obró a modo de certificado de garantía de las propuestas que llevó Buenos Aires a la mesa de negociación. A mediados de 2002 Argentina retornó al crecimiento económico sobre el cual uno de los principales responsables fue la expansión de su comercio exterior ${ }^{5}$.

En este marco Taylor logró que Horst Köhler, director gerente del FMI, realizara un informe favorable sobre la situación económica argentina, el cual fue fundamental para la firma del acuerdo provisorio. El propósito del subsecretario estadounidense era poner de una vez por todo a Argentina en su rol de negociadora de la deuda y, de este modo, evitar la posibilidad de un nuevo default. El informe, si bien no fue aceptado por Krueger y los técnicos del organismo internacional, puso de manifiesto que el reloj de Taylor sobre el caso argentino iba mucho más rápido que el de los burócratas del FMI, por ello el ingrediente político en los términos de la negociación. Algo similar ocurrió con el acuerdo definitivo de setiembre de 2003. Pero en esta ocasión hubo nuevos elementos que facilitaron la concreción del mencionado acuerdo. Uno de ellos fue el afianzamiento de Estados Unidos en la conducción de la mesa tripartita, entre otras cosas, porque Argentina iba respondiendo a lo establecido en el acuerdo provisorio y consolidando su economía, al tiempo que había realizado elecciones prolijas de las cuales derivó el traspaso de gobierno de Duhalde a Kirchner, en mayo de 2003.

La gravitación de Taylor fue clave tanto por el cerco que tendió en torno a la burocracia del FMI frenando su incidencia sobre el curso de la negociación, como por la interlocución que realizó para reducir la presión de algunos países del G-7 alrededor de esta negociación. También fue clave en la relación interburocrática al interior del gobierno norteamericano. La llegada del

\footnotetext{
${ }^{5} \mathrm{~A}$ pesar de la recesión en la que se encontraba el país, la exportación gracias a la devaluación fue clave entre abril y setiembre de 2002 (Rapetti, 2005). Precisamente en el intercambio mundial, las commodities irrumpieron con enorme gravitación tanto por el volumen como por el precio. El alza de los precios fue espectacular, porque en aquel año aumentaron el $224 \%$ en comparación con 1972. Entre 2002 y 2003 las exportaciones argentinas se incrementaron notablemente mediante cereales, pienso para animales, semillas, petróleo y derivados y aceites de origen vegetal. Pero en esos años, gracias a la demanda mundial de alimentos, Argentina comenzó a convertirse en el tercer exportador de soja después de Estados Unidos y Brasil.
} 
secretario de Estado Colin Powell a Buenos Aires y su reunión con Kirchner fue un apoyo político que mejoró el clima de la negociación por el cual bregaba Taylor, después de la indiferencia que había expuesto O’Neill. Por otra parte Taylor obtuvo un apoyo político similar, cuando logró que el subsecretario de Estado para Asuntos del Hemisferio Occidental, Roger Noriega, mitigara su enfoque crítico sobre la política doméstica de Argentina que había llegado a niveles cuasi confrontativos por su lenguaje cargado de una alta cuota ideológica. Más aún, Noriega llegó a reclamarle flexibilidad al FMI. Sin embargo lo más representativo del peso de Taylor, fue que el nuevo presidente argentino ratificó a Lavagna como ministro de Economía. A partir de este hecho político la negociación alcanzó consistencia, y la acción de Lavagna se transformó en decisiva.

La premisa de base que Argentina no estuvo dispuesta a abandonar, era que su propuesta de reestructuración de los vencimientos de deuda fuera claramente sustentable, y sin aplicar medidas de ajuste en detrimento del desarrollo de la economía nacional y la integración social. De esta forma Lavagna dejó sentada su gran diferencia con el FMI que Taylor consintió. Este prestó su aprobación porque más allá de su discrepancia con Krueger y los burócratas del medio multilateral, vio con muy buenos ojos la actitud de Argentina de darle una respuesta seria y convincente a los acreedores privados de bonos en default. El manejo de Lavagna de esta respuesta encendió diferencias con Kirchner a propósito de las concesiones que el ministro de Economía realizaba para que los bonistas aceptaran la propuesta argentina. Curiosamente el FMI y el presidente, que como señalamos tenían desacuerdos con Lavagna, libraron entre si una batalla retórica a través de la cual los burócratas subrayaban las desprolijidades de la economía del país, mientras Kirchner cuestionaba a éstos por haber empujado a Argentina a la frustración internacional y la desidia.

El acuerdo definitivo de tres años pactado en Dubai durante la asamblea anual del FMI y el Banco Mundial, se consideró un éxito en términos económicos. La refinanciación de la deuda argentina con organismos internacionales por más de 20.000 millones de dólares, la quita del $75 \%$ del valor nominal sobre la deuda de capital en default a los acreedores privados que sumaban casi 100.000 millones de dólares y el pasaje del superávit fiscal primario del $2.5 \%$ al $3 \%$ del PBI en lugar de pasar del 3.5\% en 2004 al 5\% en 2006 como pretendía el FMI, fueron algunos de los resultados más trascendentes que obtuvo Argentina en la negociación tripartita. Argentina a cambio de estos resultados, además de cumplir con las condiciones preliminares a la negociación, se comprometió -entre otras cuestiones- a modificar el régimen impositivo, la ley de coparticipación federal y el sistema bancario. En los detalles de estas cuestiones Estados Unidos prácticamente no participó y los dejó librados al entendimiento entre Argentina y el FMI. Es decir, dio por terminada la triangulación.

Lo que a Washington en todo momento le interesó era la coronación de los acuerdos, como también en esa época le preocupaba la negociación de Brasil con el FMI por un nuevo préstamo. En el caso de Argentina, el acuerdo de setiembre de 2003 significó para Estados Unidos evitar que prosperara una fuente de conflicto perturbadora de la política regional. Jus- 
tamente cuando el organismo multilateral y los ministros de Finanzas del G-7, reunidos en febrero de 2004 en Boca Ratón intentaron que los bonistas formaran parte de la negociación por los títulos en cesación de pagos a lo que Lavagna se oponía, Taylor intercedió a favor del ministro de Economía con el fin de garantizar la oferta argentina. Por ello el funcionario norteamericano, a principios de 2005, nuevamente respaldó a Argentina en el lanzamiento del canje de bonos sin la participación del FMI. Es cierto que Lavagna había mejorado la propuesta a los bonistas, pero también es cierto que Estados Unidos retornó al ruedo negociador porque quería cerrar el caso definitivamente eludiendo las objeciones del medio multilateral.

El respaldo norteamericano representó el abandono de la indiferencia política que O’Neill había liderado hacia Argentina, pero no implicó una tentativa de vuelta a la alianza de poder configurada en los noventa entre ambos países. Los cambios en el contexto internacional y sobre todo en el regional, como la orientación política impulsada por Kirchner para su gobierno, no eran congruentes con aquel fin. Los acuerdos de Argentina con el FMI y la aceptación de la mayor parte de los bonistas de la propuesta de Dubai que alcanzó casi el 77\% del total de los títulos, fueron las respuestas económicas que Buenos Aires le brindó a Washington para reducir el default, y que la Casa Blanca aceptó. Hubo un mejoramiento transitorio del bilateralismo. Fue pasajero porque a todas luces a ambos actores, por distintas razones, sólo les interesó que la negociación tuviera un final feliz. Por ejemplo el gobierno norteamericano también tuvo expectativas políticas relacionadas con el eventual apoyo argentino a algunas de las cuestiones de su agenda internacional. Estas expectativas no formaron parte de la transacción de los acuerdos, es decir en la negociación hubo ausencia de vinculación de cuestiones, pero tales expectativas estuvieron presentes en el desarrollo de las relaciones entre ambos países.

\section{EL CONTRAPUNTO}

La relación de Argentina con el FMI no volvió a recomponerse a pesar de los acuerdos de 2003. Hubo episodios relacionados con esta realidad, como por ejemplo el retiro de Taylor y Lavagna de sus respectivos gobiernos, el subsecretario en abril de 2005 y el ministro en noviembre de ese año. Por otra parte 2005 fue un año muy importante para Kirchner porque pudo obtener una mayor legitimidad en su gestión gracias a la victoria electoral de medio término de octubre del citado año. El presidente tomó el control de la economía y persistió en su retórica de cuestionamiento al medio multilateral, sobre todo después de haber cancelado la deuda con el FMI de casi 10.000 millones de dólares, en diciembre de $2005^{6}$. Este no fue

\footnotetext{
${ }^{6}$ Argentina, desde fines de 2005, había incrementado su crítica a los organismos internacionales de crédito. Lo fue haciendo al interior del mismo FMI donde el representante argentino ante esta institución, Héctor Torres, sostuvo que el organismo internacional exigía la aplicación de medidas cuyos efectos a menudo han sido contraproducentes para las economías en desarrollo. Pero el concepto más importante que utilizó Torres con respecto al FMI fue solicitarle a este una participación lo "menos intrusiva posible" en Argentina. Diario La Nación, “Fuerte crítica de la Argentina al Fondo”, Bs. As., 23 de noviembre de 2005.
} 
un acto internacional aislado pues Rusia, Indonesia y Filipinas lo habían llevado a cabo y, principalmente, días antes de ese acto lo había efectivizado Brasil. Cuando Kirchner anunció el des-endeudamiento entendió que el país ganaba "grados de libertad para la decisión nacional” a favor de la construcción de su autonomía7. Insistió en que tal hecho era un hito porque Argentina se liberaba e independizaba del organismo internacional ${ }^{8}$.

Además de los citados episodios vinculados a la tensión entre Argentina y el FMI, hubo cuestiones fundamentales que tornaron a esa tensión en más compleja. La tensión reflotó la puja entre Kirchner y los técnicos de la institución financiera internacional, que a menudo era atenuada por la negociación de Lavagna con Taylor. En algunas ocasiones predominó la idea de que el distanciamiento entre Argentina y el FMI no tuviera repercusión mundial, mientras que en otros momentos tal distanciamiento fue más que evidente. Por ejemplo en el primer caso, la suspensión de la relación entre Argentina y el FMI en agosto de 2004 por el supuesto incumplimiento de algunas de las metas del acuerdo firmado en setiembre del año anterior, fue ocultada para que el canje de bonos no sufriera un traspié. Esta maniobra la auspició Estados Unidos. Pero hubo otra cuestión que sí tuvo trascendencia y que este país no escondió alimentando el alto voltaje que adquirió la tirantez entre el organismo internacional y Argentina, como fue el rechazo de éste al pedido de los holdouts de una solución perentoria.

En esa oportunidad Lavagna, en la $46^{\mathrm{a}}$ Reunión Anual del Banco Interamericano de Desarrollo, realizada en Okinawa en abril de 2005, impugnó por "discriminatoria" la solicitud del FMI de una resolución urgente del caso de los holdouts cuando en situaciones similares las negociaciones duraron varios años y el medio multilateral se llamó a silencio. Pero Estados Unidos se hizo eco de la demanda del FMI e intercedió a favor de los bonistas que no habían ingresado al canje de deuda, exigiéndole a Argentina una rápida respuesta a estos. El subsecretario de Finanzas del Departamento del Tesoro, Randal Quarles, que ocupó el lugar que Taylor había tenido en la mesa tripartita, le planteó la inquietud del FMI a Lavagna desde el Congreso norteamericano donde se condensaban las presiones de los holdouts. La negación argentina y por ende el fracaso de Quarles no implicó que el FMI descuidara el asunto, al contrario, lo enmarcó como uno de los más relevantes a los cuales Buenos Aires debía dar una respuesta satisfactoria e inminente.

Además de esta cuestión, el FMI le formuló otro requerimiento a Argentina como era la concreción de las reformas estructurales pendientes. También puso el énfasis en la actualización de las tarifas de los servicios públicos, principalmente de los que brindaban las empresas privatizadas. Sin embargo por encima de todas las cuestiones enumeradas existió una que, justamente, tenía que ver con la relación intrainstitucional entre la entidad financiera y Argentina, ésta como país miembro de la misma. Nos referimos al cumplimiento del artículo IV del Convenio Constitutivo del FMI concerniente a la supervisión de las políticas económicas, más específicamente de los tipos de cambio. En julio de 2006 el FMI realizó la última revisión de

\footnotetext{
${ }^{7}$ Del discurso dado en el Salón Blanco de la Casa Rosada el 15 de diciembre de 2005.

${ }^{8}$ Del discurso dado en San Fernando, Provincia de Buenos Aires, el 17 de diciembre de 2005. 
la economía argentina, y a partir de esa fecha la relación entre ambos actores prácticamente fue nula. Precisamente cuando Barack Obama como presidente electo de Estados Unidos en noviembre de 2008 designó a Timothy Geithner en el Departamento del Tesoro, éste expresó su pesimismo con respecto a Argentina si el país no se sometía a la supervisión prevista por el mencionado artículo IV. En otras palabras, Argentina se encontró en dificultades para "comenzar a construir su independencia” del FMI que creyó posible con el desendeudamiento.

\section{POLÍTICA Y FINANZAS}

A pesar de la creciente tensión entre Argentina y el FMI, el gobierno estadounidense -como señalamos más arriba- tuvo expectativas políticas alrededor del país latinoamericano en función de las cuestiones internacionales y regionales que preocupaban a Washington. Así como Argentina le dio respuestas económicas al gobierno norteamericano a través de los acuerdos de 2003, también le dio respuestas políticas. En marzo de 2005 el Congreso argentino ratificó dos instrumentos internacionales vitales para la lucha contra el terrorismo como eran la Convención Internacional para la Represión de la Financiación del Terrorismo votada en 1999 en la Asamblea General de las Naciones Unidas (ONU), y la Convención Interamericana contra el Terrorismo dispuesta en 2001 en la Asamblea Plenaria de la Organización de Estados Americanos. Un año después, en línea con el combate contra el narcotráfico, el Legislativo argentino accedió a modificar la ley contra lavado de dinero, conocida como Ley Carrió.

No sólo esas acciones desplegó Argentina en respuesta directa a lo pedido por Estados Unidos. También hubo otras que fueron valoradas positivamente por el gobierno norteamericano $^{9}$. Por otra parte en más de una ocasión Tom Shannon, secretario Adjunto de Estado para Asuntos del Hemisferio Occidental de Estados Unidos, afirmó que Argentina contribuía a la estabilidad política en Sudamérica, y habló de un bilateralismo de "relación excelente". Paralelamente Nicholas Burns, subsecretario de Estado para Asuntos Políticos, es decir el número tres en el Departamento de Estado, destacó que su gobierno consideraba a Argentina como un líder regional, al igual que Brasil, India, Sudáfrica e Indonesia.

Sin embargo las respuestas políticas dadas por Argentina y las consideraciones favorables hacia este país esbozadas por funcionarios del Departamento de Estado, no fueron suficientes para el gobierno norteamericano. Entre sus expectativas hubo una que por la importancia asignada desde

\footnotetext{
${ }^{9}$ Por ejemplo la participación en la Misión de Estabilización de las Naciones Unidas en Haití, como la posición sostenida en el ámbito de la Organización Internacional de Energía Atómica de rechazo a la proliferación nuclear y el reclamo a Irán en la ONU para que colaborara en el esclarecimiento de los hechos vinculados al atentado a la AMIA, fueron otras de las acciones importantes impulsadas por Buenos Aires y elogiadas por Washington.
} 
la Casa Blanca fue creciendo rápidamente en la agenda bilateral. Se trataba de que Kirchner colaborara en el aislamiento regional e internacional del presidente de Venezuela, Hugo Chávez. Pero la densidad de las relaciones entre Argentina y el país caribeño, históricamente inéditas, era uno de los motivos por los cuales aquella colaboración no podía prosperar. Entre los aspectos distintivos de la mencionada densidad se destacaba el intercambio comercial con saldo muy superavitario para Argentina, la provisión venezolana de fuel oil y la adquisición del gobierno bolivariano de títulos públicos argentinos no negociables en el mercado mundial por más de 5.000 millones de dólares.

El vínculo entre ambos países también fue prolífico en términos diplomáticos. Vale consignar que en cinco años firmaron 52 tratados bilaterales a través de los cuales procuraron promocionar distintas áreas temáticas. El vínculo también fue intenso en términos políticos por las relaciones interpersonales entre Chávez y Kirchner, que luego se hizo extensivo entre el líder venezolano y la presidenta Cristina Fernández. Estas relaciones interpersonales fueron bastante decisivas en las relaciones interestatales. Como consecuencia de las mismas, Kirchner apoyó sistemáticamente la incorporación de Venezuela al Mercosur, y en tal dirección apuró en Caracas la firma del Protocolo de Adhesión de éste país al bloque, en julio de 2006. El presidente argentino se había entusiasmado con la estructuración del eje Brasilia-Buenos Aires-Caracas ${ }^{10}$.

La negativa de Kirchner de aislar a Chávez explicitada a Burns cuando éste visitó Buenos Aires en febrero de 2007, significó que Estados Unidos volviera a involucrarse en la cuestión financiera de Argentina ${ }^{11}$. Por otra parte el gobierno norteamericano ya no toleraba las críticas que el presidente argentino formulaba sobre los organismos de créditos internacionales, como las había soportado desde la negociación del acuerdo de 2003 hasta la cancelación de la deuda con el FMI ${ }^{12}$. No fue casual entonces que tanto la administración Bush como la oposición demócrata, comenzaran a identificar a Kirchner a través del molde del caudillismo ${ }^{13}$. El periodismo gráfico norteamericano se hizo eco de esta identificación hasta el punto en el cual esbozó la idea del eje Buenos Aires-Caracas en base al parentesco que había entre Kirchner y Chávez en torno al concepto de populismo. Pero la nota más categórica de que Estados Unidos no consideraba a Argentina como un líder regional a pesar de que Burns lo había expresado previo a su visita a la Casa Rosada, fue la exclusión de este país de la gira de Bush por América

\footnotetext{
${ }^{10}$ Una idea de Chávez aprobada por Kirchner y el presidente de Brasil Luiz Inácio Lula da Silva, reunidos los tres líderes en ocasión del acceso de Tabaré Vázquez al gobierno de Uruguay, en marzo de 2005. La satisfacción de Kirchner por esa idea no sólo estaba relacionada con la posibilidad de fortalecer la integración regional, sino también con la intención de contrabalancear el ascendente predominio brasileño en el subcontinente, teniendo en cuenta que por iniciativa de Brasilia se había formado la Comunidad Sudamericana de Naciones (CSN), en diciembre de 2004.

${ }^{11}$ El pedido de Burns a Argentina, y también a Brasil, obedeció a la presión del Congreso norteamericano que consideraba inadmisible la influencia de Chávez en los procesos electorales de Bolivia, Nicaragua y Perú, durante 2006.

${ }^{12}$ Distinta fue la posición norteamericana ante las críticas de Lula al FMI. Es cierto que los cuestionamientos del presidente brasileño no tuvieron la sistematicidad de los realizados por los gobiernos kirchneristas, y por ello no hubo una fuerte reacción estadounidense. Sin embargo Lula fue muy duro cuando en octubre de 2008 le planteó al FMI la contradicción en la que incurría al no cuestionar profundamente a Estados Unidos y Europa por la crisis desatada ese año, principalmente por la economía norteamericana, como lo hacía cuando el problema lo generaba algún país periférico.

${ }^{13}$ Ver entrevista a Arturo Valenzuela que había sido funcionario del gobierno de Bill Clinton, y entre 2008 y 2011 , secretario Adjunto de Estado para Asuntos del Hemisferio Occidental del presidente Barack Obama. Diario La Nación, "Es un peligro que Kirchner haga la política del caudillo", Bs. As., 13 de setiembre de 2006.
} 
Latina, durante marzo de $2007^{14}$. Más aún, a pocos meses de realizada esta gira, Burns volvió a la región y en esta ocasión desistió de pasar por Buenos Aires.

A propósito de este nuevo recorrido de Burns por Brasil, Chile y Uruguay, el Departamento de Estado señaló que las relaciones bilaterales de Estados Unidos con Argentina sólo eran "buenas" por las diferencias existentes, desautorizando de esta manera a Shannon, el cual había afirmado que las mismas eran "excelentes”. Por su parte la secretaria de Estado, Condolezza Rice, en línea con el Congreso norteamericano, acusaba a Kirchner de poner en riesgo el libre mercado por quitarle su apoyo al sector privado. Todas estas acciones y expresiones no hicieron otra cosa que evidenciar la decisión de Estados Unidos de profundizar el distanciamiento con Argentina. Esta actitud no fue patrimonio del republicano Bush como se creía desde algunos sectores del gobierno argentino. El demócrata Obama le dio continuidad a esa actitud y lo demostró en la III Cumbre del G-20 realizada en Pittsburg, en setiembre de 2009 (Miranda, 2012) ${ }^{15}$.

\section{EL VETO}

Si bien Argentina se recuperó económicamente, el tema de las inversiones productivas en el país fue una preocupación cada vez mayor en el gobierno. Entre 2000 y 2005 el promedio anual de inversión extranjera directa (IED) no superó los 5.00o millones de dólares. Esto no mejoró. Las cifras de 2010 pusieron en claro que Argentina no logró revertir la situación pues del cuarto lugar que ocupaba como receptor de IED en América Latina pasó al sexto con un poco más de 6.00o millones de dólares. Precisamente entre los lustros 2000-2004 y 2006-2010, la IED en el país creció sólo el 48\% cuando en Brasil fue del 80\%, Colombia 116\% y Chile 151\%. Argentina entre 2006 y 2010 acumuló un poco más de 30.000 millones de dólares en IED cuando Brasil logró superar los 170.00o millones de dólares, México alcanzó casi los 120.000 millones de dólares, Chile pasó los 62.000 millones de dólares y Colombia se acercó a los 40.000 millones de dólares ${ }^{16}$.

Kirchner pretendió seducir a los inversores transnacionales. En setiembre de 2006 los reunió tanto en el Consejo de las Américas, como en la Bolsa de Valores de Nueva York, bajo la consigna de que invirtiendo en Argentina podían ganar "mucho dinero". Al año siguiente Cristina, como candidata presidencial, intentó algo similar cuando en el Consejo de las Américas convocó a economistas e inversores de Wall Street, y puso el énfasis en que la rentabilidad no era un pecado. Luego como presidenta, en setiembre de 2009 volvió a encontrarse con

\footnotetext{
${ }_{14}$ Ante un subcomité de la Cámara de Representantes, la secretaria de Estado Condoleezza Rice argumentó que la gira de Bush estaba destinada a "la promoción y el apoyo de las fuerzas democráticas en el mundo", y para ello el presidente norteamericano iba a recorrer Brasil, Colombia, Guatemala, México y Uruguay, descartando a Argentina como país democrático.

${ }^{15}$ En este evento de países desarrollados y en desarrollo, el presidente norteamericano no le concedió a Cristina la entrevista que ella tanto deseaba para reacomodar la agenda bilateral.

${ }^{16}$ Entre 2004 y 2009 se acumularon 36.000 millones de dólares en IED que representaron el 11\% del total de inversiones realizadas en el país.
} 
directivos de compañías norteamericanas y multinacionales, y en esta oportunidad ratificó las posibilidades que el país brindaba a la inversión sosteniendo que gracias a "los niveles de reservas" obtenidos había podido enfrentar la crisis de 2008 "de mejor manera que en otros lugares del mundo" ${ }^{17}$. El gobierno argentino, en todos los casos, exhibió al des-endeudamiento del país como su mejor carta de presentación.

Sin embargo ese esfuerzo pareció ser insuficiente para atraer inversiones a territorio argentino. En gran medida el poder político norteamericano fue responsable de que esto no ocurriera. Precisamente cuando Argentina comenzó a dar respuestas diferentes a las requeridas por Washington tratando de sostener acciones de signo autonomista, la dependencia con Estados Unidos se hizo notar. El no arribo de la inversión transnacional a Argentina fue el costo que debió soportar el país por la intercesión norteamericana. No fue fortuito el fracaso del gobierno argentino en los intentos realizados entre 2006 y 2009 destinados a lograr inversiones, a sabiendas de la necesidad que tenía el país de estos capitales para asegurar su crecimiento y, fundamentalmente, para emprender el desarrollo nacional. En 2009 la IED representó sólo el 7.7\% del total de las inversiones llevadas a cabo.

La tentativa de los gobiernos kirchneristas de procurar captar inversiones esquivando la interposición de las estructuras gubernamental y burocrática norteamericanas, fue uno de los casos para que la citada tentativa quedara sólo en eso. Justamente el inversor tuvo en cuenta los informes y recomendaciones realizadas por esas estructuras en torno a la situación política y económica de Argentina. En este sentido el gobierno estadounidense reflotó el concepto de inseguridad jurídica como una de las principales referencias sobre la realidad argentina, concepto que había surgido con fuerza después de la tirantez entre Kirchner y Bush en la IV Cumbre de las Américas realizada en Mar del Plata, en noviembre de 2005. La apelación a esa referencia se acentuó cada vez más luego del rechazo del presidente argentino de aislar a Chávez, como describimos más arriba. Por ello no fue azaroso que Riordan Roett, académico vinculado a fondos de inversión, la banca y la CIA, como así también asesor de Obama, afirmara textualmente: "La impresión que tenemos es que las relaciones entre Argentina y Venezuela complican las relaciones con Washington"18.

Tampoco fue casual el mensaje norteamericano a los inversores de que Argentina ya no estaba entre sus prioridades hemisféricas. Prueba de ello fue la omisión del país en la gira sudamericana que, por razones estratégicas y a propósito de la cuestión colombiana, realizó Rice en marzo de 2008. El argumento del Departamento de Estado fue el estrecho lazo entre Argentina y Venezuela puesto de manifiesto a través del conflicto que se había generado en torno al caso de la "valija" de Guido Antonini Wilson. Para Peter Hakim, presidente de Diálogo Interamericano, la decisión estadounidense de que Rice evitara pasar por Argentina fue "claramente para desairarla" ${ }^{19}$. Más aún, la consideración especial que el gobierno norteamericano había

\footnotetext{
${ }^{17}$ A casi tres meses de la reunión de Cristina con directivos de compañías norteamericanas y multinacionales, Arturo Valenzuela visitó Argentina y ratificó que en el país había inseguridad jurídica, lo cual provocó una fuerte reacción de la Casa Rosada hacia el gobierno norteamericano.

${ }^{18}$ Diario Perfil, "Vamos a tener algún problema por el Valijagate”, Bs.As., 17 de febrero de 2008.
} 
tenido hacia el país como aliado extra-OTAN, sostenida a través de Armitage en 2002, quedó en el olvido. En realidad Washington, en su diseño hegemónico de Sudamérica, había dejado de tener en cuenta a Argentina como potencia regional secundaria, y en su lugar decidió ubicar a Colombia mediante un evidente apoyo militar y económico a este país (Miranda, 2011).

Además de las respuestas políticas que el gobierno argentino le brindó al estadounidense sobre cuestiones que le preocupaban como el terrorismo y el lavado de dinero, mencionadas más arriba, hubo decisiones significativas que el poder político norteamericano no quiso tener en cuenta. Una fue que Argentina no denunció ninguno de los 59 tratados bilaterales de inversión firmados en el marco del alineamiento político con Washington, entre 1990 y $2000^{20}$. Otra decisión fue el lanzamiento de la segunda operación de canje de bonos en default, en 2010. Debido en gran parte al embargo de cuentas y bienes del Estado determinado por la justicia estadounidense a pedido principalmente del "fondo buitre" NML Capital-Elliott, Argentina realizó la mencionada operación logrando una aceptación del 66\% que correspondía a más de 12.000 millones dólares de un total de 20.000 millones de dólares adeudados ${ }^{21}$. Por esta operación, y con el canje concretado en 2005, Argentina obtuvo la adhesión del 92.4\% del total de la deuda en cesación de pago. Sin embargo los "fondos buitres", que no ingresaron a ninguna de las dos operaciones de canje, incrementaron sus acciones políticas y judiciales respaldadas desde el sistema financiero internacional y los tribunales norteamericanos.

También merece citarse la promesa del gobierno argentino del pago de la deuda al Club de Paris, la cual oscilaba en 9.000 millones de dólares con intereses vencidos. El anuncio lo hizo Cristina a fines de 2008, afirmando que para ello iba a utilizar reservas del Banco Central. Por distintos motivos, entre los cuales estuvo la polémica a nivel doméstico, esta iniciativa no prosperó. Pero la razón más importante por la cual hubo demoras y frenos en la negociación respondió al rol que pretendía desempeñar el FMI en esta negociación, rol desestimado por Argentina que al mismo tiempo esperó estar acompañada por Estados Unidos, lo cual no sucedió. Así quedaba demostrado que el FMI seguía siendo el eje de la tensión entre Argentina y Estados Unidos.

A pesar de que Argentina no formó parte de la Alianza Bolivariana para los Pueblos de Nuestra América (ALBA), ni adhirió al proyecto del "Socialismo del siglo XXI" de Chávez, el poder político norteamericano no quiso ver el bilateralismo entre Argentina y Venezuela como

\footnotetext{
${ }_{19}$ Diario The New York Times, “Rice Trip to Ship Argentina in Sign of a Gronving Rift", Nueva York, 13 de marzo de 2008.

${ }^{20}$ Estos tratados formalmente denominados de Promoción y Protección Recíproca de Inversiones, eran muy generosos con los inversores, por ejemplo, mediante el reconocimiento de un "trato justo y equitativo", de no discriminación a través de la cláusula de "nación más favorecida", de protección frente a expropiaciones, y con la posibilidad de elegir un tribunal arbitral internacional en caso de conflicto de intereses. Algunos tratados, como el firmado con Estados Unidos en 1991 y que entró en vigencia en 1994, tenía disposiciones todavía más ventajosas para el inversor. Cabe destacar que Brasil firmó 32 tratados relativos a inversiones pero ninguno entró en vigencia porque el Senado los consideró inconstitucionales. Por su parte Colombia firmó 6 tratados bilaterales de inversión y ninguno estuvo vigente.

${ }^{21}$ Argentina tuvo numerosos embargos de propiedades del Estado entre residencias de embajadores acreditados ante Estados Unidos y la OEA y de agregadurías militares en ese país. También fue embargado el avión Tango 01, depósitos del Banco Central en Nueva York, activos del Banco Nación en esta ciudad y en Miami, cuentas del consulado en Miami y de la Secretaría de Turismo en el consulado en Nueva York, el satélite Acquarius SAC-D, patentes y derechos de patentes registrados pertenecientes a organismos científicos y tecnológicos. Asimismo hubo embargos a propiedades del Estado en Francia, Alemania, Bélgica e Italia.
} 
una relación económicamente densa, basada en los vínculos interpersonales de los presidentes, más allá de situaciones controversiales y desprolijidades diplomáticas. Ese poder, prácticamente como si fuera una política de Estado, prefirió investir a Argentina de chavismo para hacer más fácil su penalización sobre el país castigándolo por su oposición al FMI y al sistema financiero internacional. Washington entendió que Argentina retaba al régimen capitalista al no acoplarse a sus reglas.

En esa suerte de política de Estado mucho tuvo que ver la presión del Congreso norteamericano que en todo momento argumentó como decisiva la negativa argentina de aislar a Chávez. Precisamente legisladores republicanos y demócratas unificaron las demandas, tanto de los holdouts agrupados en American Task Force Argentina, como de la Asociación de Ganaderos de Estados Unidos, para exigirle a la Casa Blanca una mayor dureza hacia el país latinoamericano ${ }^{22}$. A partir de esta situación el gobierno estadounidense le planteó al argentino cuatro temas sobre los que tenía que responder positivamente si pretendía el desembarco de inversiones: a) regularizar su vínculo institucional con el FMI a través de la aplicación del artículo IV de revisión de la economía; b) solucionar la deuda con los bonistas que no habían aceptado el canje de 2005 y de 2010; c) resolver el default con el Club de París a través de la participación del FMI; y d) reconocer los dictámenes del Centro Internacional de Arreglo de Diferencias Relativas a Inversiones del Banco Mundial (CIADI), surgidos de la multiplicación de demandas contra el país, principalmente por solicitudes de reajuste tarifario de servicios públicos.

\section{CONCLUSIÓN}

El gobierno argentino a través de su política exterior pretendió promover una concepción autonomista, la cual puso de manifiesto mediante el discurso de esta política. También hubo decisiones de política exterior que respondieron a la mencionada concepción, y lo reflejaron algunas acciones llevadas a cabo por el país. Pero todo esto, si bien fue una condición necesaria para impulsar metas autonomistas, estuvo lejos de ser suficiente. La meta de acceder al crédito transnacional separadamente de la intermediación estadounidense y de organismos financieros internacionales no fue cumplida. La creencia de que la cancelación de deuda significaba alcanzar un objetivo autonomista, se desmoronó cuando Argentina constató que Estados Unidos era un obstáculo para alcanzar la inversión extranjera. Precisamente el mensaje estadounidense al actor inversor era que el país latinoamericano continuaba en default y, sobre todo,

\footnotetext{
${ }^{22}$ La American Task Force Argentina y la Asociación de Ganaderos de Estados Unidos presentaron un proyecto de ley para que el Ejecutivo bloqueara la importación de carnes argentinas, aquellos alentaron tal proyecto como medida de represalia y estos para proteger su producción. Por otra parte es importante señalar que la American Task Force Argentina desarrolló un lobby sistemático y autosostenido, entre otras cosas, enviando cartas y notas a distintos funcionarios del gobierno norteamericano, de las cuales destacamos por su tenor, la que le hicieron llegar a Rice y al secretario del Tesoro, Henry Paulson, con fecha 16 de agosto de 2007. Ver, www.atfa.org, consultado el 8 de agosto de 2011.
} 
que era portador de inseguridad jurídica.

La intercesión norteamericana empujó al sistema financiero internacional a quitarle espacio a Argentina, en consecuencia Estados Unidos reprodujo la situación de dependencia que el gobierno de nuestro país había querido reducir. Así entonces Argentina sobreestimó su ilusión de que el des-endeudamiento significaba poder para el país. No fue así porque careció de capacidad para transformar el discurso y decisión autonomistas en un efecto de libertad de elección de las fuentes de financiamiento transnacional, sin condicionamientos ni presiones de terceros. Las discrepancias entre Argentina y Estados Unidos en torno a la realidad hemisférica tallaron para que el mencionado des-endeudamiento no se convirtiera en un arma política. A la negativa de Argentina de aislar internacionalmente a Chávez, por citar un caso, el gobierno estadounidense le respondió impugnándola para maniobrar en el ámbito financiero, demostrándole a nuestro país que todavía formaba parte de su esfera de influencia a pesar de los cambios en los contextos regional y mundial.

\section{REFERENCIAS BIBLIOGRÁFICAS}

Bologna, Alfredo (2010) "La autonomía heterodoxa de la política exterior de Néstor Kirchner”, en Autores Varios, La política exterior de Cristina Fernández. Apreciaciones promediando su mandato. Rosario, CERIR-Universidad Nacional de Rosario, tomo V, pp.15-49.

Busso, Anabella (2009) “Cristina y el rol de Estados Unidos en la política exterior argentina: un vínculo incierto”, Anuario en Relaciones Internacionales 2009, Instituto de Relaciones Internacionales, Universidad Nacional de La Plata.

De la Balze, Felipe (2010) "La política exterior de los gobiernos Kirchner (2003-2009)", Estudios Internacionales, $\mathrm{n}^{\mathrm{0}} 166$, pp.121-140.

Falcoff, Mark (2004) “Argentina y Estados Unidos: Retorno al desencuentro histórico”, en Autores Varios, Relaciones Bilaterales entre Argentina y Estados Unidos. Pasado y presente. Washington, Woodrow Wilson Internacional Center for Scholars, pp.77-80.

Fernández Alonso, José (2006) "La reinserción financiera como eje rector de la agenda externa argentina post-default”, en Autores Varios, La política exterior del gobierno de Néstor Kirchner, Rosario, CERIR-Universidad Nacional de Rosario, vol.1, tomo IV, pp.31-88. 
Gil Villegas, Francisco (1989) "El estudio de la política exterior en México: enfoques dominantes, temas principales y una propuesta teórico-metodológica”, Foro Internacional, México, vol. 29, $\mathrm{n}^{\circ} 4$ (116), pp.662-692.

Girón, Alicia (2002) Crisis financieras. México, Rusia, Brasil, Turquía y Argentina. Instituto de Investigaciones Económicas, Universidad Nacional Autónoma de México.

Jaguaribe, Helio (1979) “Autonomía periférica y hegemonía céntrica”, Estudios Internacionales, Santiago, vol. 12, $\mathrm{n}^{\circ} 46$, pp.91-130.

Ministerio de Economía y Finanzas Públicas de la República Argentina, El comercio exterior bilateral Argentina-Estados Unidos de América, Documento de Trabajo, noviembre de 2011.

Miranda, Roberto (2003) “Argentina: autonomía en tiempos de crisis”, Relaciones Internacionales, Universidad Nacional de La Plata, ${ }^{\circ}{ }^{24}$, pp.127-140.

Miranda, Roberto (2011) "Le remplacement de l'Argentine dans le plan hégémonique pour l'Amérique du Sud”, Études Internationales, Institut Québécois des Hautes Études Internationales, Université Laval, vol.XLII, n ${ }^{0}$ 1, pp.97-116.

Miranda, Roberto (2012) "Bush-Obama y la continuidad de la sanción política a Argentina”, Intellector, Rio de Janeiro, Centro de Estudos em Geopolitica e Relações Internacionais, $\mathrm{n}^{\mathrm{0}} 16$, pp.11-30.

Morales Ruvalcaba, Daniel (2010) “La política exterior de Néstor Kirchner y el diseño de un Regional Core-State suramericano”, Contextualizaciones Latinoamericanas, Universidad de Guadalajara, $\mathrm{n}^{\mathrm{o}}$ 3, pp.5-17.

Nemiña, Pablo (2012) “Argentina: Camino del desendeudamiento (1991-2011)", Ola Financiera, UNAM, $\mathrm{n}^{0}$ 12, pp.70-88.

Puig, Juan Carlos (1971) "La vocación autonomista en América Latina. Heterodoxia y secesionismo”, Revista de Derecho Internacional y Ciencias Diplomáticas, Universidad Nacional de Rosario, $\mathrm{n}^{\mathrm{0}}$ 37-38, pp.21-34.

Rapetti, Martín (2005) La macroeconomía argentina durante la post-convertibilidad: Evolución, debates y perspectivas, Observatorio Argentina, Programa de Graduados en Asuntos Internacionales (GPIA), New School University, Policy Paper $\mathrm{n}^{0} 5$. 
Russell, Roberto (2010) “Argentina y Estados Unidos: una relación distante”, Agenda Internacional, $\mathrm{n}^{\circ}$ 21, pp.26-45.

Simonoff, Alejandro (2009) "Regularidades de la política exterior de Néstor Kirchner", Confines, Tecnológico de Monterrey, $\mathrm{n}^{\mathrm{0}}$ 10, pp.71-86.

Torres, Miguel (2009) "Política exterior y deuda externa en Argentina. La posición del gobierno de Cristina Fernández”, Reflexión Política, nº 22, pp.118-130.

Torres, Miguel (2011) "La autonomía en las relaciones internacionales. Las contribuciones desde el estudio de la política exterior argentina”, Estudios Internacionales de la Complutense, vol.14, $\mathrm{n}^{0} 2$, pp.103-125.

\section{CURRÍCULUM VITAE}

\section{Roberto Miranda}

Doctor en Relaciones Internacionales. Licenciado en Ciencia Política. Licenciado en Relaciones Internacionales. Investigador Independiente del Consejo Nacional de Investigaciones Científicas y Técnicas. Profesor Titular de Política Internacional Argentina, Facultad de Ciencia Política y Relaciones Internacionales, Universidad Nacional de Rosario. Profesor en la maestría y en el doctorado en Relaciones Internacionales, Instituto de Relaciones Internacionales, Facultad de Ciencias Jurídicas y Sociales, Universidad Nacional de La Plata. Director de la maestría en Relaciones Internacionales, Universidad Católica de Santa Fe.

robertoxmiranda@yahoo.com.ar 